\title{
Paradoxical Enhancement of Atherosclerosis by Probucol Treatment in Apolipoprotein E-deficient Mice
}

\author{
Sunny H. Zhang, ${ }^{*}$ Robert L. Reddick, ${ }^{*}$ Elena Avdievich, ${ }^{*}$ L. Kester Surles, ${ }^{*}$ Robert G. Jones, ${ }^{*}$ John B. Reynolds, \\ Steven H. Quarfordt, ${ }^{\ddagger}$ and Nobuyo Maeda* \\ $*$ Department of Pathology, The University of North Carolina at Chapel Hill, Chapel Hill, North Carolina 27599-7525; and ${ }^{\ddagger}$ Department of \\ Medicine, Durham VA Hospital and Duke University Medical Center, Durham, North Carolina 27705
}

\begin{abstract}
Dietary administration of probucol $(0.5 \%$, wt/wt) efficiently reduced total plasma cholesterol levels in apolipoprotein E-deficient mice (apoE-I-) by $40 \%$, with decreases in high density lipoprotein (HDL) and apoAI by 70 and 50\%, respectively. Paradoxically, however, aortic atherosclerotic plaques in the probucol-treated apoE $-I-$ mice formed more rapidly than in the untreated apoE $-I-$ mice, and the lesions were two to four times larger and more mature regardless of sex, age, and genetic background $\left(P<10^{-6}\right)$. Histologically, lesions in probucol-treated mice contained increased fibrous materials and cells other than foam cells, and were commonly associated with focal inflammation and aneurysmal dilatation. Probucol treatment also accelerated lesion development in apoE $+I-$ mice fed an atherogenic diet, indicating that the adverse effect is not dependent on the complete absence of apoE. Furthermore, mice lacking apoE and apoAI have plasma lipoprotein profiles very similar to the probucol-treated apoE $-I-$ mice, but do not have accelerated plaque development. Thus, the enhanced atherosclerosis in the probucol-treated animals is unlikely to be caused by the reduction of HDL and apoAI levels. Our data indicate that a reduction in plasma cholesterol caused by probucol does not necessarily lead to an antiatherogenic effect. (J. Clin. Invest. 1997. 99:2858-2866.) Key words: hypercholesterolemia - disease models • hypocholesterolemic agent • apolipoprotein $\mathrm{AI} \bullet$ inflammation
\end{abstract}

\section{Introduction}

Atherosclerosis results from multiple complex interactions between injurious stimuli and the responses of the arterial wall that occur in a hyperlipidemic environment. The cytotoxic activity of oxidized low density lipoproteins (LDL) and peroxidized lipids may damage the endothelium and contribute to the initiation of atherogenesis as a result of free radical chain reactions $(1,2)$. The administration of hypolipidemic drugs

\footnotetext{
Address correspondence to Dr. Nobuyo Maeda, Department of Pathology and Laboratory Medicine, The University of North Carolina at Chapel Hill, Chapel Hill, NC 27599-7525. Phone: 919-966-6914; FAX: 919-966-8800. Sunny H. Zhang's current address is Department of Obstetrics and Gynecology, University of Iowa Hospital and Clinics, Iowa City, IA 52242. Robert L. Reddick's current address is Department of Pathology, University of Texas Health Science Center, San Antonio, TX 78284-7750.

Received for publication 24 January 1997 and accepted in revised form 19 March 1997.
}

The Journal of Clinical Investigation

Volume 99, Number 12, June 1997, 2858-2866 and antioxidants is, therefore, a rational means of trying to prevent the development of atherosclerosis.

Probucol is a drug that has both cholesterol-lowering and antioxidant effects. With a free radical-scavenging phenol structure and high lipid solubility, probucol is carried within lipoprotein particles, and essentially prevents the oxidation of LDL (3). Probucol is able to reduce LDL levels via an LDL receptor-independent pathway (4), since the drug can effectively reduce cholesterol levels in homozygous LDL receptor-deficient patients. Probucol reduces HDL levels to an even greater degree. In addition, probucol reduces the storage of lipid in macrophages (5), and has been shown to reverse xanthomas in some severely hypercholesterolemic patients (5).

In experimental animal models, probucol reduced lesion development when administered to Watanabe heritable hyperlipidemic (WHHL) ${ }^{1}$ rabbits in some, but not all experiments (6-9). Probucol also inhibited atherosclerosis induced by high-fat, high-cholesterol diet in the nonhuman primate (10), but not in cholesterol-fed rabbits (11). The effects of probucol on human patients are likewise not well established. For example, a recent human trial (Probucol Quantitative Regression Swedish Trial, PQRST) has shown the ineffectiveness of probucol in retarding femoral artery atherosclerosis, despite the presence of a drug-induced reduction in cholesterol levels and antioxidant effects $(12,13)$.

In this study, we have tested the effects of probucol on mice genetically lacking apolipoprotein E (apoE). These apoE-/mice have spontaneously elevated plasma cholesterol levels, and develop atherosclerosis even on a regular low-fat/low-cholesterol diet $(14,15)$. The time-dependent progression of atherosclerotic lesions in the apoE-/- mice leads to lesions similar in histopathology to those observed in humans and other species $(16,17)$. Our results show that probucol effectively lowers the total plasma cholesterol levels in the apoE-/mice, but unexpectedly accelerates the development of their aortic atherosclerotic plaques.

\section{Methods}

Animals and experimental design. Mice were bred in-house and maintained on regular chow. Four sets of dietary probucol treatments $(0.5 /$ $100 \mathrm{~g}$ chow) were conducted using age-matched (within $10 \mathrm{~d}$ of birth) and sex-matched mice. Body weight and plasma lipid levels were monitored before the treatment, and then at every $4 \mathrm{wk}$.

Three experiments (1a through 1c) were performed with apoE-/homozygotes with regular chow. In experiments $1 \mathrm{a}$ and $1 \mathrm{~b}$, we used apoE $-/$ - mice with $>99 \%$ C57BL/6J (B6) genetic background as a result of backcrossing B6:129 F1 heterozygotes (18) to B6 for six generations before intercrossing to obtain the apoE-/- homozygotes. In

1. Abbreviations used in this paper: FPLC, fast protein liquid chromatography; IDL, intermediate density lipoprotein; WHHL, Watanabe heritable hyperlipidemic. 
experiment $1 \mathrm{a}$, nine 2 -mo-old female mice were fed chow with probucol for $3 \mathrm{mo}$, and nine were fed regular chow. In experiment $1 \mathrm{~b}$, six 3-mo-old female and four 4-mo-old male apoE-/- mice were on the probucol diet for $3 \mathrm{mo}$, and five 3-mo-old female and three 4-mo-old male apoE-/- mice were on the probucol-free diet for 3 mo before death.

In experiment 1c, 2-mo-old mice with mixed 129 and C57BL/6J (B6) genetic backgrounds were used. 13 apoE-/- mice (five male, eight female) were fed the probucol-containing chow (see below), and 14 apoE-/- mice (six male, eight female) received regular chow for 2 mo. All males and five females were killed after 2 mo of treatment. Two female mice were fed the probucol diet for an additional 2 mo before being killed. Control animals included both wild-type $($ apoE $+/+)$ and heterozygous (apoE $+/-)$ littermates of the apoE-/mice. Six female and six male controls were fed regular chow, and four female and six male controls were fed probucol-containing diet for 2 mo.

In experiment 2 , apoE $+/-$ heterozygotes were generated by crossing the B6-backcrossed apoE-/- mice with wild-type B6 animals. Six 3-mo-old apoE $+/-$ females were fed an atherogenic diet (see below) with probucol for $3 \mathrm{mo}$, and six were fed the atherogenic diet without probucol.

Mice deficient for apolipoprotein AI (apoAI) were also in B6 genetic background generated by backcrossing 129/B6 F1 heterozygotes (19) to B6 for seven generations before intercrossing to obtain homozygotes. ApoAI-/- mice were crossed with backcrossed apoE-/mice to generate mice doubly deficient for apoE and apoAI.

The animal protocols used in this study have been approved by institutional review panels.

Diets. All of the regular mouse chow used in experiment 1 had $4.5 \%$ fat (wt/wt) and $0.022 \%$ cholesterol, although the supplier varied. All mice were fed relevant control diet without probucol for $2 \mathrm{wk}$ before commencement of the experiment. Plasma cholesterol levels were measured to ensure that no animals were included that had levels substantially different from the others in their group.

In experiment $1 \mathrm{a}$, the regular control diet (C1) was prepared (No. 11708; Dyets, Inc., Bethlehem, PA), based on their AIN-93 diet to contain $0.022 \%$ cholesterol. Probucol was kindly supplied by (Daiichi Pharmaceuticals, Tokyo, Japan). The main protein and fat sources of AIN-93 are casein and soybean oil. In experiment $1 \mathrm{~b}$, regular control chow, C2 (based on CE2, CLEA JAPAN, Inc., Tokyo, Japan), and $\mathrm{C} 2$ with $0.5 \%$ (wt/wt) probucol were provided by Chugai Pharmaceuticals Co. (Gotenba, Japan). The main protein and fat sources of C2 are fish meal and soybean oil. In experiment 1c, the probucol (generously provided by Merrell-Dow Pharmaceuticals Inc., Indianapolis, IN) was dissolved in ethanol and added to the regular control diet, C3, (No. 5012; Ralston Purina Co., St. Louis, MO) to achieve a final concentration of $0.5 \%(\mathrm{wt} / \mathrm{wt})$. The ethanol was allowed to evaporate by drying in air for $48 \mathrm{~h}$. The main protein and fat sources of $\mathrm{C} 3$ are soy protein, casein, and animal fat.

An atherogenic diet containing $15.8 \%$ fat, $1.25 \%$ cholesterol, and $0.5 \%$ cholic acid was prepared (Dyet No. 11724), based on AIN-93. Probucol was from Daiichi Pharmaceuticals.

Probucol levels. In experiment 1b, the plasma probucol levels were measured on individual samples by Dr. Y. Ohba (Chugai Pharmaceuticals Co.). In experiment $1 \mathrm{c}$, probucol levels in pooled plasma were measured in the laboratory of Dr. D. Steinberg (University of California, San Diego), using high performance liquid chromatography (4).

Plasma lipid and lipoprotein analysis. Blood samples were obtained from animals fasted overnight by retroorbital bleeding, as previously described (14). Total plasma cholesterol and triglyceride levels were determined enzymatically with reagents from Sigma Chemical Co. (St. Louis, MO), or from Wako Bioproducts (Richmond, VA). HDL cholesterol was determined after removing apolipoprotein B-containing particles by a magnesium/dextran sulfate precipitation method (20); plasma samples from apoE-/- mice were diluted 1:3 with phosphate-buffered saline before the precipitation procedure. All the measurements were done in duplicates. The apoAI amounts in plasma samples were compared by densitometric analysis of Coomassie blue-stained or silver-stained bands after nonreducing SDS-polyacrylamide gel electrophoresis (21). Relative levels of plasma apoAI, apoAIV, and apoE were also measured densitometrically using a chemiluminescent procedure (ECL kit; Amersham Corp., Arlington Heights, IL) on Western blots using rabbit antisera against mouse apoAI or apoAIV (gifts from Dr. H. DeSilva, University of North Carolina, Charlotte), and goat anti-human apoE antiserum (Calbiochem Corp., San Diego, CA). Total lipoproteins from pooled plasma were isolated by ultracentrifugation with density adjusted to $1.21 \mathrm{~g} / \mathrm{ml}$ using $\mathrm{KBr}$ (14). Lipoprotein fractions, equivalent to $100 \mu \mathrm{l}$ plasma in control mice and $30 \mu \mathrm{l}$ plasma in apoE-/- mice, were loaded in each lane and subjected to SDS-PAGE using a 4-20\% gradient gel; staining was with Coomassie blue. The size distributions of plasma lipoproteins were analyzed by fast protein liquid chromatography (FPLC) using a Superose 6 HR10/30 column (Pharmacia LKB Biotechnology Inc., Piscataway, NJ) with pooled plasma (50 or $100 \mu \mathrm{l}) .0 .5-\mathrm{ml}$ fractions were collected at a flow rate of $0.4 \mathrm{ml} / \mathrm{min}$

Evaluation of atherosclerotic lesions. Mice were killed with an overdose of Avertin (Aldrich Chemical Co., Milwaukee, WI). The heart and the arterial tree were perfused with phosphate-buffered paraformaldehyde (4\%, pH 7.4) under physiological pressure. Serial cryosections of the proximal aorta and the aortic sinus were made and stained with Sudan IVB (Fisher Scientific Co., Pittsburgh, PA), and counterstained with hematoxylin. Hematoxylin and eosin-stained sections were used for histological evaluations. Average lesion sizes of four sections, spanning the region from the very proximal aorta to the point in the aortic sinus that contains three complete valve leaflets, were used for the morphometric evaluations based on the methods by Paigen et al. (22). Whole aortas, from the descending aorta to the iliac bifurcation, were isolated from each mouse, and all the fatty tissue in the adventitia was stripped away with fine dissection forceps. The gross image of the aortas was photographed (M420 microscope; Wild Heerbrugg Instruments, Inc., Farmingdale, NY) and the lesion sizes were measured by quantitating the lesion-covered areas on the aortic vessel walls (NIH image 1.57 program; National Institutes of Health, Bethesda, MD).

Statistics. The Student's $t$ test of unpaired two-sample means was used to compare plasma lipid levels and aortic lesion sizes (as logarithms) in the probucol-treated mice with the corresponding values of the untreated mice in each experiment.

\section{Results}

Probucol efficiently reduces plasma cholesterol levels in apoEdeficient mice. We observed no significant changes in body weight or general health of the mice fed $0.5 \%$ (wt/wt) probucol in their diet compared to mice fed the control diet. The total cholesterol levels found in animals $4 \mathrm{wk}$ after commencement of probucol treatment were stably maintained throughout the remainder of all experiments. Comparisons of plasma lipid levels between probucol-treated and -untreated mice at the end of each treatment protocol are summarized in Table I. In experiments $1 \mathrm{a}$ and $1 \mathrm{~b}$, carried out with B6-backcross apoE-/- animals, plasma cholesterol levels in the probucol-treated females were $39 \%$ lower than those in untreated females $\left(P<10^{-4}\right)$. Plasma total cholesterol in all four male mice in experiment $1 \mathrm{~b}$, also reduced by an average of $30 \%$ compared to their levels before the probucol treatment $(P=0.03)$. Comparisons with untreated mice were not significant, partly because of the small number of mice used. In experiment $1 \mathrm{c}$, carried out with mice of B6:129 mixed genetic background, total plasma cholesterol levels in probucol-treated apoE-/- female mice were $66 \%$ lower than in untreated mice $\left(P<10^{-5}\right)$, while total plasma cholesterol in probucol-treated control $($ apoE $+/+$ or 
Table I. The Effects of Probucol on Plasma Lipid Levels

\begin{tabular}{|c|c|c|c|c|c|c|c|c|c|c|}
\hline Exp & Diet & ApoE & Sex & $n$ & BW & $\mathrm{TC}$ & TG & HDLC & ApoAI & Probucol \\
\hline \multirow[t]{2}{*}{$1 \mathrm{a}$} & $\mathrm{C} 1$ & $-1-$ & $\mathrm{F}$ & 9 & $24 \pm 3$ & $406 \pm 71$ & $88 \pm 42$ & $23 \pm 11$ & $100 \pm 6$ & \\
\hline & $\mathrm{C} 1+\mathrm{P}$ & $-1-$ & $\mathrm{F}$ & 9 & $25 \pm 2$ & $248 \pm 49^{\S}$ & $69 \pm 34$ & $13 \pm 8^{\ddagger}$ & $50 \pm 10^{\S}$ & ND \\
\hline \multirow[t]{4}{*}{$1 \mathrm{~b}$} & $\mathrm{C} 2$ & $-1-$ & $\mathrm{F}$ & 5 & $21 \pm 3$ & $542 \pm 101$ & $63 \pm 13$ & $14 \pm 6$ & ND & \\
\hline & $\mathrm{C} 2+\mathrm{P}$ & $-1-$ & $\mathrm{F}$ & 6 & $23 \pm 2$ & $330 \pm 78^{\ddagger}$ & $67 \pm 12$ & $9 \pm 6$ & ND & $49.6 \pm 15.7$ \\
\hline & $\mathrm{C} 2$ & $-1-$ & $\mathrm{M}$ & 3 & $28 \pm 2$ & $637 \pm 104$ & $121 \pm 48$ & $28 \pm 7$ & ND & \\
\hline & $\mathrm{C} 2+\mathrm{P}$ & $-1-$ & $\mathrm{M}$ & 4 & $27 \pm 3$ & $479 \pm 91$ & $77 \pm 25$ & $31 \pm 11$ & ND & $56.2 \pm 3.8$ \\
\hline \multirow[t]{4}{*}{$1 \mathrm{c}$} & $\mathrm{C} 3$ & $+/ *$ & $\mathrm{~F}$ & 6 & $22 \pm 6$ & $83 \pm 22$ & $67 \pm 18$ & $68 \pm 20$ & 100 & \\
\hline & $\mathrm{C} 3+\mathrm{P}$ & $+/ *$ & $\mathrm{~F}$ & 4 & $21 \pm 1$ & $17 \pm 8^{\S}$ & $77 \pm 11$ & $15 \pm 6^{\S}$ & 48 & $6.7 \pm 1.2$ \\
\hline & $\mathrm{C} 3$ & $-1-$ & $\mathrm{F}$ & 8 & $22 \pm 2$ & $573 \pm 101$ & $79 \pm 24$ & $53 \pm 23$ & 100 & \\
\hline & $\mathrm{C} 3+\mathrm{P}$ & $-1-$ & $\mathrm{F}$ & 8 & $25 \pm 1$ & $194 \pm 54^{\S}$ & $79 \pm 27$ & $21 \pm 8^{\ddagger}$ & 48 & $53.4 \pm 16.4$ \\
\hline \multirow[t]{2}{*}{2} & $\mathrm{HF}$ & $+/-$ & $\mathrm{F}$ & 6 & $21 \pm 1$ & $215 \pm 47$ & $20 \pm 5$ & ND & $100 \pm 6$ & \\
\hline & $\mathrm{HF}+\mathrm{P}$ & $+/-$ & $\mathrm{F}$ & 6 & $22 \pm 1$ & $170 \pm 18$ & $21 \pm 7$ & ND & $57 \pm 16^{\ddagger}$ & ND \\
\hline
\end{tabular}

Diets are with $(+\mathrm{P})$ or without probucol in control chow $(\mathrm{C} 1, \mathrm{C} 2, \mathrm{C} 3)$ or in high-fat diet $(\mathrm{HF})$. Control animals $+/ *$ in experiment $1 \mathrm{c}$ included both wild-type and heterozygous animals. $F$, females; $M$, males; Exp, experiment; $B W$, body weight (g); $T C$, total plasma cholesterol (mg/dl); $H D L C, H D L$ cholesterol $(\mathrm{mg} / \mathrm{dl}) ; T G$, triglyceride $(\mathrm{mg} / \mathrm{dl})$. ApoAI levels are expressed as a mean value of the respective control as 100 . Probucol levels are in $\mu \mathrm{g} / \mathrm{ml}$. $N D$, not determined. ${ }^{\ddagger} 0.001<P<0.05,{ }^{\S} P<0.001$, against the corresponding levels in untreated animals by Student's $t$ test.

apoE $+/-$ ) females was reduced by $80 \%$ compared to untreated mice $(P<0.0005)$. Reduction in plasma cholesterol levels in probucol-treated male animals having this genetic background was similarly significant (data not shown). The hypocholesterolemic effect of probucol treatment was also observed in heterozygous $(\mathrm{E}+/-)$ mice fed a diet containing high fat and high cholesterol (experiment 2). The total plasma cholesterol levels of the apoE $+/-$ female mice fed the high-fat $\operatorname{diet}(215 \pm 47 \mathrm{mg} / \mathrm{dl})$ were increased by $\sim 120 \mathrm{mg} / \mathrm{dl}$ compared to their prefeeding levels (data not shown), while the increase in the animals consuming the diet containing probucol was $\sim 80 \mathrm{mg} / \mathrm{dl}$. Thus, probucol efficiently lowers the plasma cholesterol levels in apoE-deficient animals.

Cholesterol levels in both apolipoprotein B-containing lipoproteins and HDL were reduced in the probucol-treated animals, although the extent of reduction of the cholesterol in these two classes of lipoproteins was different in animals of the different genotypes. In apoE $+/+$ and apoE $+/-$ mice, $89 \%$ of the reduction was in HDL cholesterol levels, while in the apoE $-/-$ mice, 92 (experiment 1c) to $95 \%$ (experiment $1 \mathrm{~b}$ ) of the reduction was in the cholesterol of apolipoprotein B-containing particles. The reductions in HDL levels were significant $(P<0.01)$ in experiments 1 a and $1 c$, but no difference was observed in experiment $1 \mathrm{~b}$. The variability in the HDL-C values in these experiments may be a consequence of variability in the removal of VLDL-IDL (intermediate density lipoprotein) fraction by precipitation when VLDL-IDL cholesterol is high. We note, however, that the observed reduction in HDL cholesterol after probucol treatment is supported by the results of FPLC analysis presented in Fig. 1 below. No significant difference between treated and untreated animals in triglyceride levels was observed in any of the experiments.

The plasma probucol levels in the apoE $-/-$ mice treated with probucol for $3 \mathrm{mo}$ in experiment $1 \mathrm{~b}$ were $46.9 \pm 15.7 \mu \mathrm{g} / \mathrm{ml}$ $(n=6)$ in females, and $56.2 \pm 3.8 \mu \mathrm{g} / \mathrm{ml}(n=4)$ in males. The plasma probucol levels in mice treated with probucol for $2 \mathrm{wk}$ in experiment $1 \mathrm{c}$ were $53.4 \pm 16.4 \mu \mathrm{g} / \mathrm{ml}(n=3)$ in the apoE-lmice, and $6.7 \pm 1.2 \mu \mathrm{g} / \mathrm{ml}(n=5)$ in the apoE $+/+$ or $+/-$ mice. Thus, the probucol levels reached in the apoE $-/-$ mice were equivalent to those reported in human patients $(20-90 \mu \mathrm{g} / \mathrm{ml})$ with familial hypercholesterolemia on conventional therapeutic doses $(1 \mathrm{~g} / \mathrm{d})(23)$.

Marked reduction in HDL cholesterol and plasma apoAI levels by probucol treatment. To evaluate the reduction in each class of lipoprotein by probucol more precisely, the size distributions of plasma lipoproteins in the probucol-treated and -untreated female mice in experiments $1 \mathrm{a}$ and 2 were determined by FPLC (Fig. 1). Over $90 \%$ of the cholesterol in both probucol-treated and -untreated apoE-/- mice was in the large remnant particles that elute in the VLDL and IDL range (fractions 14-25, Fig. $1 \mathrm{~A}$, open circles) for untreated mice as reported previously (14). Cholesterol in the VLDL-IDL fractions of the probucol-treated apoE-/- mice (fractions 14-25, Fig. $1 B$, filled circles) was $\sim 40 \%$ that of the nontreated mice. Reduction in HDL cholesterol (fractions 28-31, Fig. 1, $A$ and $B$ ) was more marked, by $\sim 70 \%$ in both apoE- $-1-$ mice fed regular diet, and in the apoE $+/-$ mice fed the atherogenic diet. Reduction by probucol in particles in the IDL range (by $31 \%$, fractions $19-25$ in Fig. $1 B$ ) was also similar in the apoE $+/-$ mice fed the atherogenic diet to that in the apoE-/mice fed the regular chow, while the reduction in VLDL was less $(13 \%)$ and variable at different times (data not shown).

Parallel to the reduction in HDL levels, a substantial decrease in total plasma apoAI levels was observed in both control (apoE $+/+$ or apoE $+/-)$ and apoE-/- mice. Fig. 2 illustrates this reduction in total plasma apoAI levels by silver-stained nonreducing SDS-PAGE. The reduction determined by densitometry of apoAI in pooled plasma was the same $(52 \%$ reduction by densitometry scanning) in both the apoE-/- mice and the control $($ apoE $+/+$ or apoE $+/-)$ mice fed regular chow (Fig. 2). ApoAI levels measured by Western blot and densitometry in individual plasma samples of probucol-treated mice from experiment $1 \mathrm{a}$ and experiment 2 were $50 \pm 10$ and $57 \pm 16 \%$, respectively, that of mice fed the control diets. ApoAIV amounts in probucol-treated plasma were also reduced (to $77 \pm 27$ and $71 \pm 20 \%$, respectively, of untreated), but the difference was not statistically significant. ApoE amounts in high fat-fed apoE $+/-$ mice did not differ in the probucol- 
A

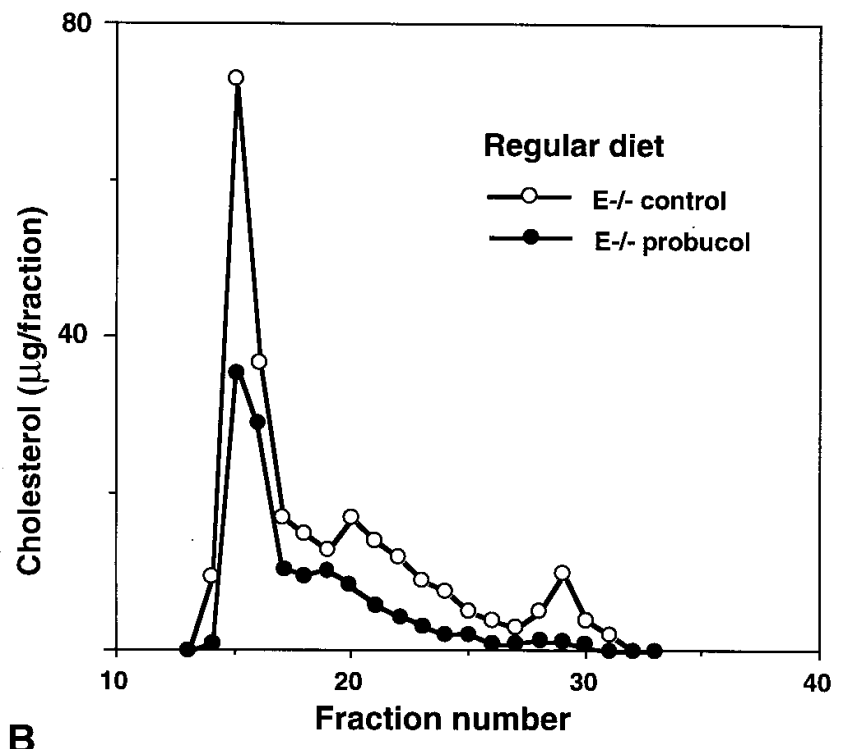

B

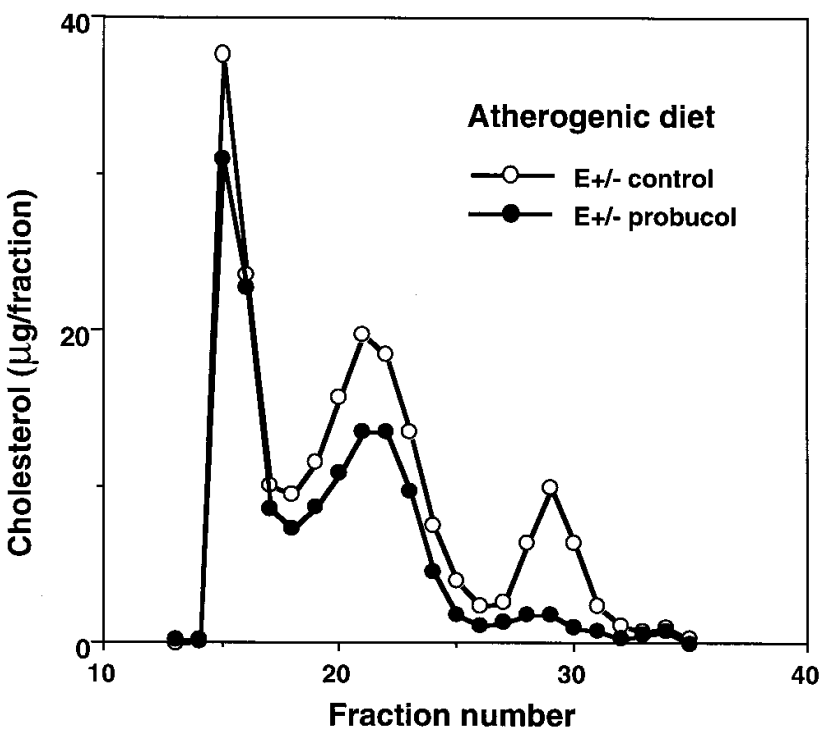

Figure 1. Lipoprotein FPLC profiles with $(A)$ pooled plasma $(50 \mu \mathrm{l})$ from apoE $-/-$ mice on a regular diet, and $(B)$ pooled plasma $100 \mu \mathrm{l}$ from apoE $+/-$ mice on the atherogenic diet. Filled and open circles indicate probucol-treated animals and untreated animals, respectively.

treated and untreated groups. Apolipoprotein compositions after SDS-PAGE of lipoprotein fractions in the probucoltreated mice did not show any obvious differences from those in the untreated mice except for the above noted parallel reductions of apoAI, apo AIV, apoB48 in the apoE -/- mice, and the control mice treated with probucol (data not shown).

Enhancement of atherosclerotic lesion development by probucol treatment. A total of 57 probucol-treated and -untreated apoE-/- mice were examined for the development of atherosclerosis in their aortic sinus and proximal aorta of the animals after a standard protocol, essentially as described by Paigen et al. (22). Experiment 1a was the largest single experiment, with 18 age-matched apoE-/- females fed regular chow with (nine

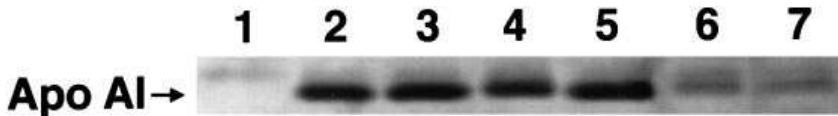

Figure 2. Plasma total apoAI levels determined by silver staining after nonreducing SDS-PAGE. $1 \mu \mathrm{l}$ of plasma pooled from three to five animals was applied to each lane. Only the bands corresponding to apoAI are shown. Lane 1 , apoAI $-1-$ and apoE $-1-$ untreated; lanes 2 and 5 , apoE +/+ (normal) untreated; lane 3, apoE +/- untreated; lane 4 , apoE $-/-$ untreated; lane 6 , apoE $-/-$ probucoltreated; lane 7, apoE $+/+$ (normal) probucol-treated. All the animals had a mixed C57BL/6J:129 genetic background.

animals) or without (nine animals) probucol. The mean lesion sizes of the individual animals (Fig. $3 A$ ) shows that the lesions in all of the nine mice treated with probucol in this experiment were larger than any of the lesions in the nine untreated mice with no overlap. The logarithmic mean area was three times larger in the probucol-treated mice compared to that in the untreated mice $\left(335,000\right.$ vs. $\left.98,000 \mu \mathrm{m}^{2}, P<10^{-6}\right)$. Table II summarizes the results from experiments $1 \mathrm{~b}$ and $1 \mathrm{c}$. Experiments $1 \mathrm{~b}$ and $1 \mathrm{c}$ are directly comparable to experiment $1 \mathrm{a}$, except that they are with smaller numbers of males and females. Additionally, experiment 1c was with mice having a mixed B6:129 genetic background. In all experiments, the probucol-treated mice had larger plaques than the untreated mice (Table II). Female mice had larger lesions on both the regular diet and the probucol diet than did male mice at the same age. The mice in experiment $1 \mathrm{c}$ had smaller lesions than mice in experiments $1 \mathrm{a}$ and $1 \mathrm{~b}$, partly because the former mice were younger, and partly because they had a mixed B6:129 genetic background compared to the latter group of mice which were backcrossed onto the inbred B6 genetic background. The $P$ values of the lesion sizes in the probucol-treated groups compared to those of respective control groups were all significant except in males in experiment $1 \mathrm{c}(P=0.059$ was not significant). Thus, without exception, the data from these two addi-
A

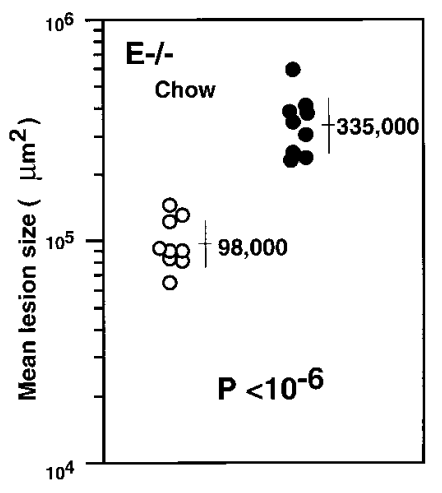

B

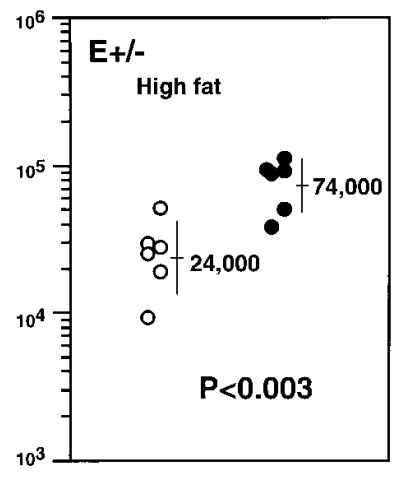

Figure 3. The effect of probucol on the size of atherosclerotic lesions. $(A)$ apoE $-/-$ mice on regular diet, and $(B)$ apoE $+/-$ mice on the atherogenic diet. Each point represents the mean lesion size of four sections from each mouse. Filled circles represent probucol-treated mice, and open circles represent untreated mice. Horizontal bars and the numbers represent the logarithmic mean value in $\mu \mathrm{m}^{2}$ of lesion size from each group of mice. The vertical bars represent the range of logarithmic mean \pm SD in logarithmic scale. 


\begin{tabular}{|c|c|c|c|c|c|c|c|c|}
\hline \multirow[b]{2}{*}{ Exp } & \multirow[b]{2}{*}{ Mice } & \multirow[b]{2}{*}{ Diet } & \multirow[b]{2}{*}{ Sex } & \multicolumn{2}{|c|}{ Age (mo) } & \multicolumn{2}{|c|}{ Mean lesion area* } & \multirow[b]{2}{*}{$P$} \\
\hline & & & & Start & End & Probucol-treated & Untreated & \\
\hline & & & & & \multicolumn{4}{|c|}{$\mu m^{2} \times 10^{-3}$} \\
\hline $1 \mathrm{a}$ & $-/-$, B6 & $\mathrm{C} 1$ & $\mathrm{~F}$ & 2 & 5 & $335(246-455), n=9$ & $98(75-126), n=9$ & $<10^{-6}$ \\
\hline \multirow[t]{2}{*}{$1 \mathrm{~b}$} & $-/-, \mathrm{B} 6$ & $\mathrm{C} 2$ & $\mathrm{~F}$ & 3 & 6 & $532(345-822), n=5$ & $263(184-377), n=5$ & 0.024 \\
\hline & & & $\mathrm{M}$ & 4 & 7 & $603(564-644), n=3$ & $402(353-457), n=3$ & 0.017 \\
\hline \multirow[t]{2}{*}{$1 \mathrm{c}$} & $-/-$, B6:129 & $\mathrm{C} 3$ & $\mathrm{~F}$ & 2 & 4 & $85(50-146), n=5$ & $25(15-42), n=6$ & 0.0045 \\
\hline & & & $\mathrm{M}$ & 2 & 4 & $23(16-33), n=5$ & $12(6-21), n=6$ & 0.059 \\
\hline 2 & $+/-, \mathrm{B} 6$ & $\mathrm{HF}$ & $\mathrm{F}$ & 2 & 5 & $74(48-113), n=6$ & $24(14-42), n=6$ & 0.003 \\
\hline
\end{tabular}

$F$, females; $M$, males; $H F$, high fat; Exp, experiment. C1, C2, and C3 are regular mouse chow containing $4.5 \%$ fat and $0.022 \%$ cholesterol (see Methods). Ages of mice are in months at the beginning and the end of diet treatment. *Mean lesion areas are logarithmic means; the areas one logarithmic standard deviation on either side of the means are in parentheses.

tional experiments also demonstrate that probucol treatment enhances atherosclerotic plaque development in apoE-/mice regardless of sex, age, genetic background, and the source of the diet.

To test whether the adverse effect of probucol was the result of the complete lack of apoE in the $-/-$ mice, we also examined heterozygous apoE $+/-$ mice which produce about half the normal level of apoE. ApoE $+/-$ mice do not develop lesions when maintained on regular chow diet, but consistently do so when fed an atherogenic diet (24). Accordingly, the apoE $+/-$ females were fed the atherogenic diet with or without probucol. The results are presented in Fig. $4 B$ and in Table II as experiment 2 . We found that the mice consuming the atherogenic diet containing $0.5 \%$ (wt/wt) probucol again had larger lesions $(P<0.003)$. These results establish, therefore, that the enhanced plaque development does not depend on the complete lack of apoE. The data also indicate that probucol not only accelerates the growth of existing plaques of apoE-/- mice, but also accelerates plaque formation in apoE $+/-$ mice.

To determine whether accelerated lesion progression by probucol in apoE-deficient mice occurs only in the aortic sinus and in the proximal aorta, we carried out lesional histomorphometry in the descending area from the aortic arch to the iliac bifurcation. Examination of five probucol-treated female mice in experiment $1 \mathrm{~b}$, in which treatment began at 3 mo of age when lesions are not usually detected in the descending aorta (16), revealed that all had greater number and larger plaques in the descending aorta than in the four untreated animals, which had only a few small lesions. The areas covered by the lesions in the descending aorta of the probucol-treated mice $\left(5.4 \pm 1.0 \mathrm{~mm}^{2}\right)$ were four times those in the untreated mice $\left(1.4 \pm 0.5 \mathrm{~mm}^{2}\right)$. Thus, enhancement of atherosclerosis by probucol occurs throughout the aortic tree of apoE mice.

Lesions in probucol-fed mice are more mature than those in controlmice. Histological examination was carried out by light microscope of the serial sections of aortic sinus and proximal aorta. As illustrated in Fig. 4, sections even at low magnification revealed that, compared to the atherosclerotic lesions in nontreated mice (Fig. $4 A$ ), the lesions in mice treated with probucol for 3 mo (Fig. 4, $B-D$ ) were not only larger but also more mature. The lesions in the nontreated mice were mainly composed of foam cells with small acellular areas adjacent to the media (Fig. $4 \mathrm{~A}$ ). Lesions in the probucol-treated mice contained fewer lipids, but were more fibrous and contained cells other than foam cells. Inflammation within plaques as well as in adventitia was evident (Fig. 4 B). Strikingly, large aneurysmal areas were frequently present in the probucoltreated animals with the B6 genetic background. Thus, we found that seven of the nine probucol-treated mice in experiment 1a had large aneurysmal dilatation in the aortic sinus, as illustrated in Fig. 4, $C$ and $D$. In contrast, none of the nine untreated control group had large aneurysmal dilatations; one had a sign of media thinning in the similar area. Thinning and weakening of the media commonly occurs at or near a coronary ostium, and typically involves large outpockets filled with plaque materials, calcific deposits, necrosis, and inflammatory cells (Fig. $4 \mathrm{C}$ ). Extensive fibrosis in adventitial tissues indicates chronic inflammation surrounding the aneurysm (Fig. $4 \mathrm{D}$, lower right quadrant). Despite their large sizes, these aneurysms appear to be asymptomatic. Aneurysms of this type are often noted in older apoE-/- mice. Whether their frequent occurrence at the relatively young age of 5 mo in the present experiment is a primary effect of the probucol treat-

Figure 4. Comparison of aortic lesions of probucol-treated and nontreated apoE $-/-$ mice. $A$ and $B$ show cross-sections of the aorta near the aortic sinus from the 5-mo-old mice fed control diet and probucol diet, respectively. Sudan IVB and hematoxylin staining; $\times 45$. $(C)$ Thinning of media near a coronary ostium representing aneurysmal dilatation commonly seen in probucol diet-fed mice; $\times 45$. $(D)$ Cross-section of proximal aorta from another mouse showing an aneurysm filled with plaque material. Evaluation of nearby sections show that this aneurysm originated near a ostium similar to $C$. Extensive fibrosis in the area surrounding aneurysmal outpockets is present; $\times 45$. $(E)$ A plaque in proximal aorta from an untreated mouse showing collection of intact foam cells. A cellular area is present adjacent to media; $\times 90$. $(F)$ A plaque in a probucoltreated mouse contains punctate lipid droplets, a fibrous cap, and focal inflammatory infiltration; $\times 90$. $G$ and $H$ show cross-sections of the proximal aorta from 4-mo-old apoE -/- mice with a B6:129 mixed genetic background fed regular diet and probucol diet, respectively. Hematoxylin and eosin staining, $\times 110$. 

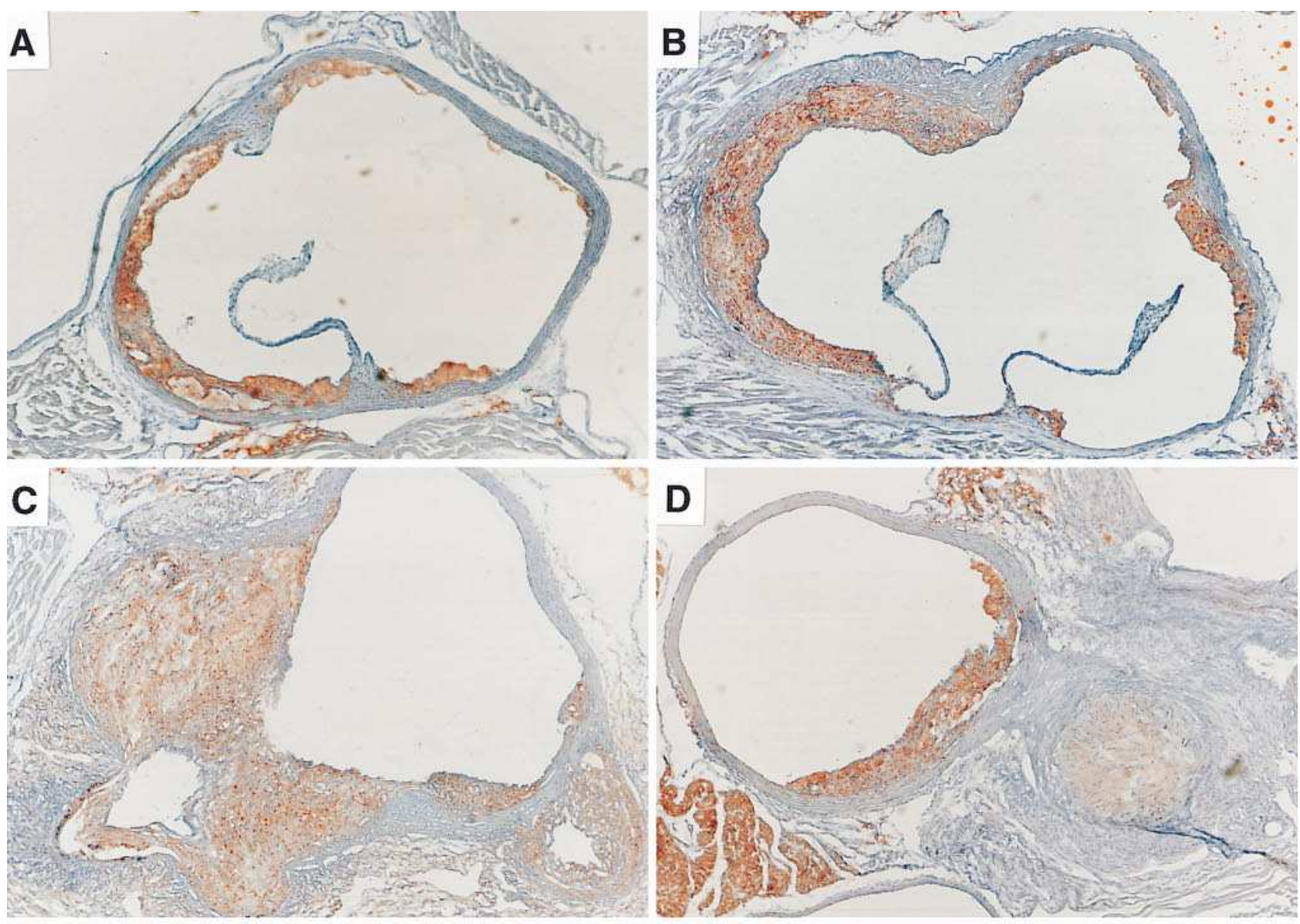

E
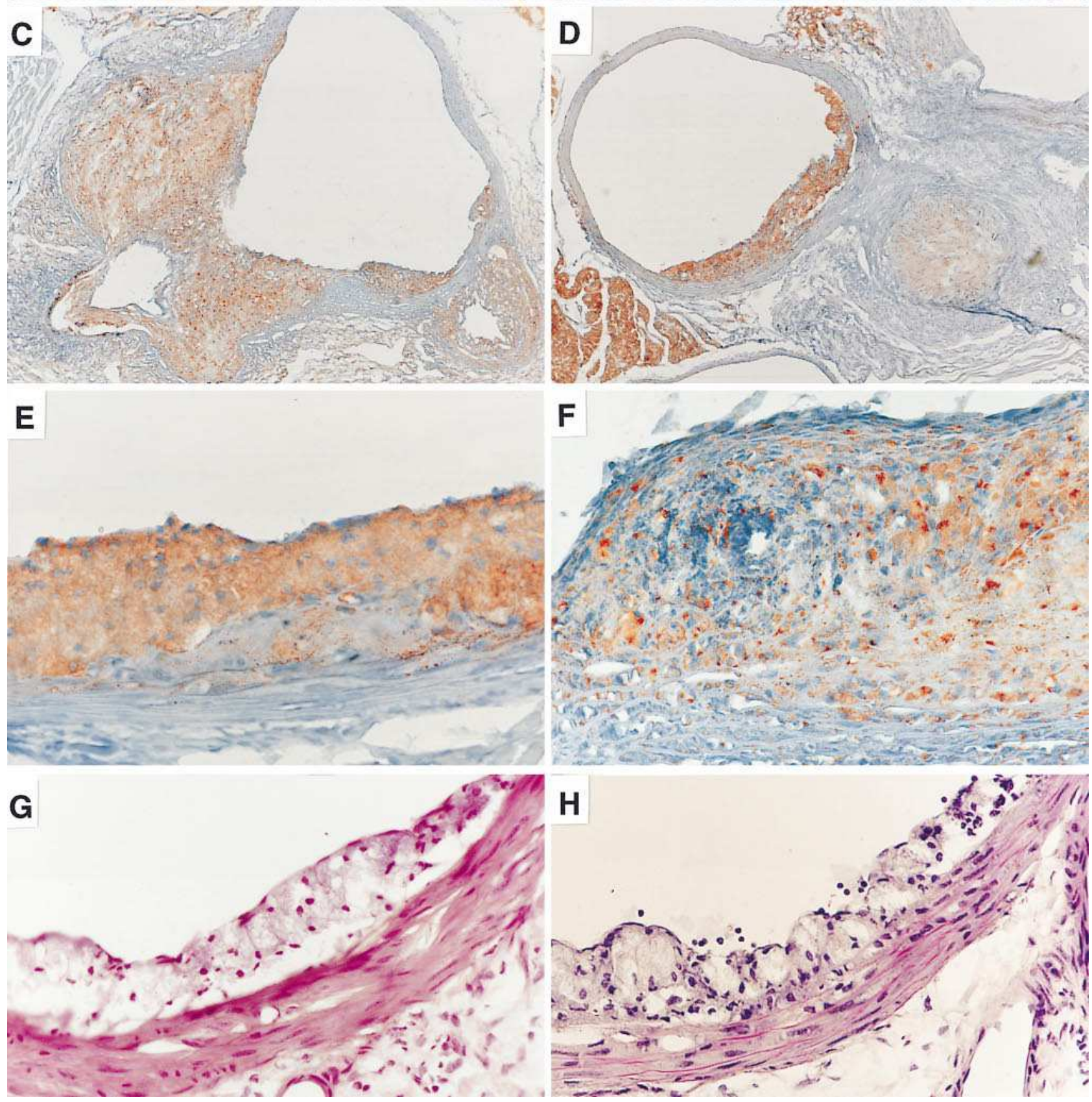
Table III. Effect of ApoAI Deficiency on Plasma Lipid Levels and Atherosclerotic Lesion Development in ApoE-deficient Mice

\begin{tabular}{cccccc}
\hline Sex & Genotype $(n)$ & TC & TG & HDLC & Mean lesion area \\
\hline & $m g / d l$ & $m g / d l$ & $m g / d l$ & $\mu m^{2} \times 10^{-3}$ \\
Females & AAee (14) & $467 \pm 115$ & $72 \pm 25$ & $34 \pm 14$ & $106(50-227), n=8$ \\
aaee (12) & $315 \pm 67^{*}$ & $66 \pm 28$ & $17 \pm 11^{*}$ & $60(27-133), n=8$ \\
Males & AAee (12) & $560 \pm 81$ & $117 \pm 47$ & $43 \pm 18$ & $67(37-122), n=12$ \\
& aaee (8) & $388 \pm 159^{\ddagger}$ & $78 \pm 33^{\ddagger}$ & $13 \pm 10^{*}$ & $48(43,54), n=2$
\end{tabular}

$T C$, total plasma cholesterol; $T G$, triglyceride; $H D L C$, HDL cholesterol. ${ }^{*} P<0.001,{ }^{\ddagger} 0.001<P<0.05 .{ }^{\circledR}$ Mean lesion areas are logarithmic means; the areas one logarithmic standard deviation on either side of the means are in parentheses.

ment itself, or is secondary to the increased plaque growth, is currently unknown.

At higher magnifications, the lesions in the untreated mice showed a dense accumulation of lipid-filled foam cells near the surface, and the lipid present within the plaque was largely intracellular (Fig. $4 \mathrm{E}$ ). A well-defined fibrous cap was not present. In contrast, the lesions in the probucol-treated mice showed diffuse and punctate staining for lipids, suggesting that the lipid was mainly extracellular (Fig. $4 F$ ). Sparse collections of intact foam cells were seen near the surface. Well-defined fibrous caps and cholesterol clefts were present. Focal inflammation within the plaques was common in the probucoltreated animals (Fig. $4 F$ ). In 4-mo-old mice with a mixed genetic background, both on a regular diet (Fig. $4 G$ ) and on a probucol diet (Fig. $4 \mathrm{H}$ ) for $2 \mathrm{mo}$, the lesions were characterized mainly by foam cell depositions without fibrous cap formation. Notable difference, however, between the lesions in the probucol-treated and the -untreated mice of this group was that a significant number of mononuclear cells was commonly seen on or near the surface of lesions in the probucol-treated mice (Fig. $4 H$ ), but rarely in the untreated mice (Fig. $4 G$ ). This type of accumulation of mononucleated cells was not seen in the mature lesions of either regular diet or drug-treated mice. Taken together, these comparisons suggest that the lesions in the probucol-treated mice are in general more mature than in the untreated mice, with more inflammatory cells present in the lesions of the treated animals.

Reduced HDL cholesterol and apoAI are not causes of the adverse effects of probucol. Since the levels of plasma HDL cholesterol have been shown to be inversely associated with atherosclerosis in various studies (25), the adverse effect on the development of atherosclerosis seen with probucol treatment of apoE-deficient mice may be the result of the dramatic reduction of HDL cholesterol that accompanies the treatment. To test this possibility, we intercrossed apoE-/- mice with apoAI-/- mice that lack apoAI and have markedly reduced plasma HDL cholesterol levels (19). To minimize the effects of other genetic loci, the mice with the apoE mutation and with the apoAI mutation were individually backcrossed towards B6 before the intercross. The total plasma cholesterol levels (Table III) in female and male mice lacking both apoAI and apoE (aaee) were significantly lower (by $\sim 40 \%$ ) than those in the apoE-/- mice (AAee). The HDL cholesterol levels in the aaee mice were also significantly lower, as shown by enzymic measurements (Table III), and by FPLC analysis (data not shown), in which $>95 \%$ of cholesterol in the aaee mice was in particles in the VLDL range; cholesterol in the HDL range was almost undetectable. Note that the levels and distributions of plasma cholesterol in the AAee mice with probucol are very similar to those in the aaee mice.

The mean lesion areas in the aaee mice were, however, not significantly different from those in the AAee mice (Table III). Because the B6 backcrossed mutants do not breed well, we were only able to evaluate a limited number of aaee mice at 4 mo of age during the last 2 yr. Furthermore, during this period, the colony environment, including air handling and bedding materials, was changed because of factors beyond our control. Consequently, the data in Table III show wider variations in lesion sizes in all the mice than normal (results varied from one animal to the other by over 10 -fold). Nevertheless, in all these tests, the lesions in aaee mice were fewer than those in the AAee (in contrast to the threefold larger lesions seen in the AAee mice that had reduced levels of apoAI when treated with probucol). Together, the results make it very unlikely that the enhanced lesion formation accompanying probucol treatment is caused by the reduced HDL cholesterol and plasma apoAI levels.

\section{Discussion}

In this study, the effects of probucol on plasma cholesterol levels and atherosclerotic lesion development in apoE-/- mice were evaluated using mice with either a B6 inbred genetic background or with a mixed B6:129 genetic background. As expected from previous studies in humans and in other animals (including mice), probucol markedly reduced the total cholesterol, HDL cholesterol, and total plasma apoAI levels in all the apoE $-/-$ mice studied. Probucol also effectively reduced the extent of dietary-induced hypercholesterolemia in apoE $+/-$ mice in response to the atherogenic diet.

Probucol reduces LDL cholesterol levels by enhancing the removal of LDL (26), and it has been hypothesized that probucol achieves this reduction by incorporating into LDL particles, and thereby altering their structures (3). This effect is thought to be mediated through an LDL receptor-independent pathway, since probucol is effective in lowering LDL cholesterol in homozygous familial hypercholesterolemic patients, and in homozygous WHHL rabbits, both of which lack the LDL receptor. In apoE-/- mice, hypercholesterolemia is the result of accumulation of VLDL and chylomicron remnants as a consequence of the lack of apoE, a ligand having a high affinity for LDL and other receptors. We found here that probucol significantly reduces the levels of the atherogenic remnant particles in mice lacking apoE, and that this hypolipidemic effect occurs to a similar extent (21-66\% reduction) to the effects of probucol in WHHL rabbits (24\% reduction) $(4,6)$ with similar plasma levels of the drug. Consequently, our data demonstrate that probucol is capable of reducing plasma cholesterol levels through apoE-independent pathway(s).

Various modes of action of probucol have been described in different species (27-31). In the rat, its hypocholesterolemic effect appears to result predominantly from a decrease in absorption of cholesterol (28), whereas in humans and mice it results mainly from the stimulation of catabolic excretion through the bile $(27,28)$. Tawara et al. (27) have shown that probucol treatment in normal mice results in an accelerated 
clearance of $\left[{ }^{14} \mathrm{C}\right]$ cholesterol-derived radioactivity from the circulation, accompanied by an increased fecal radioactivity excretion and an increase in hepatic cholesterol $7 \alpha$-hydroxylase activity. Cholesterol synthesis in the drug-treated mice was not changed. Our preliminary observation, that cholesterol $7 \alpha-$ hydroxylase mRNA levels are significantly elevated by probucol in apoE-/- mice (unpublished observation), agrees with these findings, and suggests that probucol lowers cholesterol, at least partly, by increasing bile excretion in these mice despite the fact that plasma cholesterol-containing lipoproteins cannot be efficiently taken up by the liver in the absence of apoE. It is possible that the reduction in plasma cholesterol in the apoE-/- mice results from a reduced output of lipoproteins secondary to an increased rate of conversion of cholesterol to bile acids in the liver.

Contrary to what might be expected from the cholesterol-lowering effect of probucol, however, the present study showed that probucol not only did not retard atherosclerosis in our apoE $-/-$ mice, but actually accelerated lesional development. This paradoxical result was consistently seen in three independent experiments carried out at different times, with different sources of diet, with animals of different genetic backgrounds, and with both male and female mice. The probucol treatment enhanced atherosclerotic lesions in animals in which treatment commenced at 2 mo of age, an age at which minimal lesions are found in the aortas. The treatment also enlarged the lesions in animals that were 4 mo old at the start of treatment, an age when full-blown atherosclerotic lesions covered with fibrous caps are already present. The combined $P$ value for the effect of probucol on lesions is considerably less than $10^{-6}$.

The inverse relationship between the cholesterol level and lesion size that we have observed in our apoE-/- mice after probucol treatment has not been reported in any other previous experiments, although its ineffectiveness in retarding femoral artery atherosclerosis has been observed in a human trial (12), and lack of effect on atheroma formation was also reported in some of the animal experiments $(8,11)$. Our observation of enhanced atherosclerosis by probucol in apoE-deficient mice is further surprising in view of probucol's strong antioxidant activity. A number of antioxidants have been shown to have antiatherogenic effects (32) and Tangirala et al. (33) reported that treatment with $N, N^{\prime}$-diphenyl 1,4-phenylenediamine, a different class of antioxidant compound from probucol, was effective in reducing atherosclerosis in apoE-/mice fed a high-fat diet containing $0.15 \%$ cholesterol (33).

The marked reduction of apoAI and HDL cholesterol must be considered as one possible explanation for the accelerated atherosclerosis by probucol in the apoE-deficient mice. Our observation that mice lacking both apoAI and apoE do not show an accelerated development of atherosclerosis (although their HDL cholesterol levels are markedly reduced), however, argues that this is unlikely to be the major explanation of our findings.

Although the mechanisms underlying the enhancement we observed are not known, probucol may be affecting directly the atherogenic process in the apoE-deficient mice. For example, others have suggested that the subtle balance of plasma and tissue antioxidants may be altered in the presence of high amounts of probucol in the plasma (34). Here, we have noted an increased mononuclear cell attachment to the atherosclerotic lesions of the apoE-/- mice after probucol treatment; this attachment was more evident in the nonmatured foam cell lesions than in the matured fibrous cap lesions. An accumulation of monocytes on the surface of the endothelium after probucol treatment has also been reported in rats (35). These several findings suggest that probucol might be inducing monocyte attractant factors in the vessel wall, which could be expected to accelerate the atherogenic process. Furthermore, we commonly observed focal inflammation within mature plaques and inflammatory cell-induced alterations of the adventitia in the aorta of the probucol-treated animals. Interestingly, we also observed that mice fed probucol for $3 \mathrm{mo}$ had significantly larger spleens than untreated mice $(0.16 \pm 0.05$ vs. $0.09 \pm 0.02 \mathrm{~g}$ in apoE $-1-$ mice in experiment $1 \mathrm{a}, n=9, P<$ $0.01 ; 0.13 \pm 0.02$ vs. $0.09 \pm 0.01 \mathrm{~g}$ in apoE $+/-$ in experiment 2 , $n=6, P<0.005)$. Histologically, the spleens were indicative of reactive splenomegaly. No proinflammatory changes at a tissue level associated with high concentration of probucol have been described previously. Further studies are necessary to evaluate the influence of probucol on inflammatory processes in these strains of mice.

Probucol has a high affinity for lipids, and its rate of clearance is dependent on the rate of clearance of plasma lipid. Even after probucol treatment, the cholesterol level in the apoE-/- mice $(200 \mathrm{mg} / \mathrm{dl})$ is 10 -fold higher than the level in the probucol-treated apoE $+/+$ or apoE $+/-$ mice $(20 \mathrm{mg} / \mathrm{dl})$. Concomitantly, there is about a 10 -fold higher plasma probucol level in the apoE-/- mice than in the apoE $+/+$ or apoE $+/-$ mice, so that the plasma probucol level is proportional to the plasma cholesterol level in these mice. The plasma probucol levels in the apoE $-/-$ mice $(50 \mu \mathrm{g} / \mathrm{ml})$ were comparable to those seen in treated WHHL rabbits, or in human patients administered the conventional therapeutic dose. The possibility needs to be considered, however, that the chronic presence of such high levels of probucol in plasma (which can be reached in the presence of hyperlipidemia in mice) might be harmful. Further studies of the effects of probucol on atherogenesis in other mouse models, such as the LDL receptor-deficient mice (36) or the human apolipoprotein B transgenic mice $(37,38)$, should be undertaken to clarify whether the adverse effect is related to the lack or insufficiency of apoE-mediated mechanism(s) in the apoE-/- mice, or to the high-fat diet which is fed to the apoE+/- mice. Beneficial effect of probucol in WHHL rabbits, and its detrimental effect in apoE-deficient mice, is a species-specific difference. Whatever the cause of the actual existence of this proves to be, our data suggest the need for further investigations of the effects of long-term probucol treatment, particularly in markedly hyperlipidemic patients.

In summary, we have demonstrated that probucol markedly enhances the development of atherosclerosis in the mice lacking apoE, and in mice having reduced levels of apoE in spite of its ability to cause significant reductions in total plasma cholesterol. Our data indicate that the measurement of total plasma cholesterol levels may not in itself be sufficient to document the effectiveness of probucol treatment.

\section{Acknowledgments}

We thank S. Kim, J. Tyson, and B. Oswald for technical help, Drs. D. Steinberg and Y. Ohba for determining plasma probucol levels in the mice, Drs. S. Ishibashi and $\mathrm{H}$. deSilva for providing us the cholesterol $7 \alpha$-hydroxylase cDNA probe and antisera, Dr. T. Kodama for his 
help in arranging the supply of probucol, and Drs. O. Smithies and J. Osada for their critical reading of this manuscript.

This work was supported by National Institutes of Health research grant HL-42630 to N. Maeda.

\section{References}

1. Schwartz, C.J., A.J. Valente, E.A. Sprague, J.L. Kelley, and R.M. Nerem. 1991. The pathogenesis of atherosclerosis: an overview. Clin. Cardiol. 14:I1-I16.

2. Ross, R. 1993. The pathogenesis of atherosclerosis: a perspective for the 1990s. Nature (Lond.). 362:801-809.

3. Parthasarathy, S., S.G. Young, J.L. Witztum, R.C. Pittmann, and D. Steinberg. 1986. Probucol inhibits oxidative modification of low density lipoprotein. J. Clin. Invest. 77:641-644.

4. Naruszewicz, M., T.E. Carew, R.C. Pittman, J.L. Witztum, and D. Steinberg. 1984. A novel mechanism by which probucol lowers low density lipoprotein levels demonstrated in the LDL receptor-deficient rabbit. J. Lipid Res. 25: 1206-1213.

5. Yamamoto, A., Y. Matsuzawa, S. Yokoyama, T. Funahashi, T. Yamamura, and B. Kishino. 1986. Effects of probucol on xanthomata regression in familial hypercholesterolemia. Am. J. Cardiol. $57: 29 \mathrm{H}-35 \mathrm{H}$.

6. Kita, T., Y. Nagano, M. Yokode, K. Ishii, N. Kume, A. Ooshima, H. Yoshida, and C. Kawai. 1987. Probucol prevents the progression of atherosclerosis in Watanabe heritable hyperlipidemic rabbit, an animal model for familial hypercholesterolemia. Proc. Natl. Acad. Sci. USA. 84:5928-5931.

7. Nagano, Y., T. Nakamura, Y. Matsuzawa, M. Cho, Y. Ueda, and T. Kita. 1992. Probucol and atherosclerosis in Watanabe heritable hyperlipidemic rabbit-long-term antiatherogenic effect and effects on established plaques. Atherosclerosis. 92:131-140.

8. Daugherty, A., B.S. Zweifel, and G. Shonfeld. 1991. The effects of probucol on the progression of atherosclerosis in mature Watanabe heritable hyperlipidemic rabbits. Br. J. Pharmacol. 103:1013-1018.

9. Braesen, J.H., U. Beisiegel, and A. Niendolf. 1995. Probucol inhibits not only the progression of atherosclerotic disease, but causes a different composition of atherosclerotic lesions in WHHL-rabbits. Virchows Arch. 426:179-188.

10. Sasahara, M., E.W. Raines, A. Chait, T.E. Carew, D. Steinberg, P.W. Wahl, and R. Ross. 1994. Inhibition of hypercholesterolemia-induced atherosclerosis in the nonhuman primate by probucol. I. Is the extent of atherosclerosis related to resistance of LDL to oxidation? J. Clin. Invest. 94:155-164.

11. Stein, Y., O. Stein, B. Delplanque, J.D. Fesmire, D.M. Lee, and P. Alaupovic. 1989. Lack of effect of probucol on atheroma formation in cholesterol-fed rabbits kept at comparable plasma cholesterol levels. Atherosclerosis. 75:145-155.

12. Walldius, G., U. Erikson, A.G. Olsson, L. Bergstrand, K. Hadell, J. Johansson, L. Kaijser, C. Lassvik, J. Molgaard, and S. Nilsson. 1994. The effect of probucol on femoral atherosclerosis: the Probucol Quantitative Regression Swedish Trial (PQRST). Am. J. Cardiol. 74:875-883.

13. Regnstrom, J., G. Walldius, S. Nilsson, L.S. Elinder, J. Johansson, J. Molgaard, I. Holme, A.G. Olsson, and J. Nilsson. 1996. The effect of probucol on low density lipoprotein oxidation and femoral atherosclerosis. Atherosclerosis. 125:217-229.

14. Zhang, S.H., R.L. Reddick, J.A. Piedrahita, and N. Maeda. 1992. Spontaneous hypercholesterolemia and arterial lesions in mice lacking apolipoprotein E. Science (Wash. DC). 258:468-471.

15. Plump, A.S., D.J. Smith, T. Hayek, K. Aalto-Setala, A. Walsh, J.G. Verstuyft, E.M. Rubin, and J.L. Breslow. 1992. Severe hypercholesterolemia and atherosclerosis in apolipoprotein E-deficient mice created by homologous recombination in ES cells. Cell. 71:343-353.

16. Reddick, R.L., S.H. Zhang, and N. Maeda. 1994. Atherosclerosis in mice lacking apolipoprotein E: evaluation of lesional development and progression. Arterioscler. Thromb. 14:141-147.

17. Nakashima, Y., A.S. Plump, E.W. Raines, J.L. Breslow, and R. Ross. 1994. ApoE-deficient mice develop lesions of all phases of atherosclerosis throughout the arterial tree. Arterioscler. Thromb. 14:133-140.
18. Piedrahita, J.A., S.H. Zhang, J.R. Hagaman, P.M. Oliver, and N. Maeda. 1992. Generation of mice carrying a mutant apolipoprotein E gene inactivated by gene targeting in embryonic stem cells. Proc. Natl. Acad. Sci. USA. 89:4471-4475.

19. Williamson, R., D. Lee, J. Hagaman, and N. Maeda. 1992. Marked reduction of high density lipoprotein cholesterol in mice genetically modified to lack apolipoprotein A-I. Proc. Natl. Acad. Sci. USA. 89:7134-7138.

20. Warnick, G.R., J. Benderson, and J.J. Albers. 1982. Dextran sulfate$\mathrm{Mg}^{2+}$ precipitation procedure for quantitation of high-density-lipoprotein cholesterol. Clin. Chem. 28:1379-1382.

21. France, D.S., T.E. Hughes, R. Miserendino, J.A. Spirito, J. Babiak, J.B Eskesen, C. Tapparelli, and J.R. Paterniti, Jr. 1989. Nonimmunochemical quantitation of mammalian apolipoprotein $\mathrm{AI}$ in whole serum or plasma by nonreducing gel electrophoresis. J. Lipid. Res. 30:1997-2004.

22. Paigen, B., A. Morrow, P.A. Holmes, D. Mitchell, and R.A. Williams 1987. Quantitative assessment of atherosclerotic lesions in mice. Atherosclerosis. 68:231-240.

23. Baker, S.G., B.I. Joffe, D. Mendelsohn, and H.C. Seftel. 1982. Treatment of homozygous familial hypercholesterolaemia with probucol. S. Afr. Med. J. 62:7-11

24. Zhang, S.H., R.L. Reddick, B. Burkey, and N. Maeda. 1994. Diet-induced atherosclerosis in mice heterozygous and homozygous for apolipoprotein $\mathrm{E}$ gene disruption. J. Clin. Invest. 94:937-945.

25. Gordon, D.J., and B.M. Rifkind. 1989. High-density lipoprotein: the clinical implications of recent studies. N. Eng. J. Med. 321:1311-1316.

26. Nestel, P.J., and T. Billington. 1981. Effects of probucol on low density lipoprotein removal and high density lipoprotein synthesis. Atherosclerosis. 38: 203-209.

27. Tawara, K., M. Tomikawa, and Y. Abiko. 1986. Mode of action of probucol in reducing serum cholesterol in mice. Jpn. J. Pharmacol. 40:123-133.

28. Beynen, A.C. 1986. Discrepancies between the outcome of animal and human studies on the mode of action of probucol. Atherosclerosis. 61:249-251.

29. Atmeh, R.F., M.J. Stewart, D.E. Boag, C.J. Packard, A.R. Lorimer, and J. Shepherd. 1983. The hypolipidemic action of probucol: a study of its effects on high and low density lipoproteins. J. Lipid Res. 24:588-595.

30. Hayek, T., T. Chjek-Shaul, A. Wals, N. Azrolan, and J.L. Breslow. 1991. Probucol decreases apolipoprotein AI transport rate and increases high density lipoprotein cholesterol ester fractional catabolic rate in control and human apolipoprotein AI transgenic mice. Arterioscler. Thromb. 11:1295-1302.

31. Steinberg, D. 1986. Studies on the mechanism of action of probucol. Am. J. Cardiol. $57: 16 \mathrm{H}-21 \mathrm{H}$

32. Bjorkham, I., A. Henrucksson-Freyschuss, O. Breuer, U. Diczfalusy, L. Berglund, and P. Henrikson. 1991. The antioxidant butylated hydroxytoluene protects against atherosclerosis. Arterioscler. Thromb. 11:15-22.

33. Tangirala, R.K., F. Casanada, E. Millwe, J.L. Witztum, D. Steinberg, and W. Palinski. 1995. Effect of the antioxidant $N, N^{\prime}$-diphenyl 1,4-phenylenediamine (DPPD) on atherosclerosis in apoE-deficient mice. Arterioscler Thromb. 15:1625-1630.

34. Elinder, L.S., K. Hadell, J. Johansson, J. Molgaard, I. Holme, A.G. Olsson, and G. Walldius. 1995. Probucol treatment decreases serum concentrations of diet-derived antioxidants. Arterioscler. Thromb. Vasc. Biol. 15:1057-1063.

35. Snankar, R., J.D. Sallis, H. Stanton, and R. Thomson. 1989. Influence of probucol on early experimental atherogenesis in hypercholesterolemic rats. Atherosclerosis. 78:91-97.

36. Ishibashi, S., J.L. Goldstein, M.S. Brown, J. Herz, and D.K. Barns. 1994. Massive xanthomatosis and atherosclerosis in cholesterol-fed low density lipoprotein receptor-negative mice. J. Clin. Invest. 93:1885-1893.

37. Purcell-Huynh, D.A., R.V. Farese, Jr., D.F. Johnson, L.M. Flynn, V. Pierotti, D.L. Newland, M.F. Linton, D.A. Sanan, and S.G. Young. 1995. Transgenic mice expressing high levels of human apolipoprotein B develop severe atherosclerotic lesion in response to a high-fat diet. J. Clin. Invest. 95:22462257

38. Callow, M.J., J. Verstuyft, R. Tangirala, W. Palinski, and E.M. Rubin. 1995. Atherogenesis in transgenic mice with human apolipoprotein B and lipoprotein (a). J. Clin. Invest. 96:1639-1646. 